Article

\title{
Integrative Neuromuscular Training in Young Athletes, Injury Prevention, and Performance Optimization: A Systematic Review
}

\author{
Borja Sañudo ${ }^{1, * \mathbb{C}}$, Juan Sánchez-Hernández ${ }^{1}$, Mario Bernardo-Filho ${ }^{2}$, Ellie Abdi ${ }^{3}$, \\ Redha Taiar ${ }^{4}\left(\mathbb{\circ}\right.$ and Javier Núñez ${ }^{5}$ \\ 1 Departamento de Educación Física y Deporte, Universidad de Sevilla, E-41013 Seville, Spain; \\ juan_28256@hotmail.com \\ 2 Departamento de Biofísica e Biometria, Universidade do Estado do Rio de Janeiro, 22050-032 Rio de Janeiro, \\ Brazil; bernardofilhom@gmail.com \\ 3 Center of Pedagogy, Montclair State University, Upper Montclair, NJ 07043, USA; ellieabdi@verizon.net \\ 4 Département d'Education Physique et sportive (EPS), Université de Reims, 51687 Reims, France; \\ redha.taiar@univ-reims.fr \\ 5 Departamento de Deporte e Informática, Universidad Pablo de Olavide, 41704 Seville, Spain; \\ fjnunsan@upo.es \\ * Correspondence: bsancor@us.es; Tel.: +34-652-387090
}

Received: 6 August 2019; Accepted: 10 September 2019; Published: 12 September 2019

\begin{abstract}
The aim of this systematic review was to evaluate the current evidence by assessing the effectiveness of integrative neuromuscular training programs in injury prevention and sports performance in young athletes. Different data sources were analyzed up to January 2018. Eligible studies contained information on population (young athletes), intervention (neuromuscular training), comparator (control group or another exercise intervention), outcomes (injury prevention or sport performance), and study design (randomized trials or prospective studies). The trials were restricted based on the language (English) and for publication date (after 1 January 2007). Fourteen randomized controlled trials were included: Seven included dynamic stability-related outcomes. Three assessed the coordination performing fundamental movements and sport-specific skills, while other five studies analyzed muscle strength and two assessed plyometric tests. Agility was evaluated in three studies and speed tests were also considered by four studies. Finally, fatigue resistance in three studies and injury risk in four were assessed. This review provides evidence that integrative neuromuscular training programs can enhance performance and injury prevention in young athletes, taken into account that adherence to the training program is adequate. Collectively, well-designed, randomized studies are necessary to collaborate with the present findings.
\end{abstract}

Keywords: neuromuscular training; strength; injury prevention; young athletes

\section{Introduction}

Integrative neuromuscular training (INT) is defined as a training program aimed to enhance physical fitness and prevent the aggregation of the neuromuscular deficits, along with the improvements of the motor competence, especially in youth with a lower level of motor skills [1]. This type of training in sync with the improved sports-related movement skills could also have an impact on injury prevention [2]. Further, recent literature has displayed that the absence of this training's type before or during the adolescence can lead to imbalances and incorrect movement patterns. This fact might be associated with a greater injury risk [3-5], especially in young female athletes [6] and in those sports involving a high number of landings or change of direction maneuvers, such as football or 
basketball [7]. Although young athletes present a lower injury ratio in comparison with adults, these injuries entail a longer recovery period. The injuries could even lead to a cessation of the practice due to fear of recurrence [8], with consequent effect on their careers as athletes $[9,10]$.

Recently, Fort-Vanmeerhaeghe et al. [11] developed a classification of the INT components that included two blocks: (a) The first block focused on the development of fundamental movement skills, which includes coordination, strength, plyometric, agility, dynamic stability, speed, and fatigue resistance training, and (b) in the second block sport-specific movement skills were included [11]. It is suggested that all these contents must be exercised in order to improve performance and reduce injury risks. By coordination, within the fundamental movement skills, authors usually refer to locomotor, manipulation, and stability skills (variety of movements and multitasking, including unanticipated reactions). It is believed that these abilities allow control and optimize different sport-specific movements, thus decreasing the injury risks in youth athletes [11]. Additional aspects, such as strength, have been extensively analyzed in the literature. Resistance training might include core and lower limb positions and stability but also the application of upper-body and lower-body exercises and pushing/pulling strength exercises [11]. Strength deficits have been associated with less neuromuscular control and increasing the appearance of injuries in the young population [12].

Moreover, plyometric [13], considered as the development of stretch shortening cycle ability and agility training (development of skills at maximum speed integrating changes of direction actions) [11] also have been suggested in order to improve the performance and decrease injury risks in this population group. Literature also highlighted dynamic stability training (balance training that includes dynamic actions) as a means to manage neuromuscular control because of the improvements in the sensorimotor system, which enhances joint dynamic stability and may also reduce the risk of injury in youth athletes [14]. Furthermore, it seems that speed is the main determinant in the performance of many sports. The inability to produce speed in sprint, optimally during childhood, may decrease the possibility of achieving high competitive levels [15]. This term is closely related with agility and would include the development of skills at maximum speed [11]. On the other hand, fatigue resistance training could be defined as the development of skills under fatigue conditions [11]. It is known that neuromuscular fatigue is an important risk factor in numerous sports injuries [16].

Despite the importance of this type of training, especially in young athletes, the number of studies that include all INT contents in their intervention programs is scarce. The knowledge on its effect of injury prevention and performance has to be determined in this population. Therefore, this systematic review focuses on the analysis of the current evidence assessing the effectiveness of INT programs on injury prevention and sports performance in young athletes.

\section{Methods}

\subsection{Eligibility Criteria}

For this systematic review, the Preferred Reporting Items for Systematic Reviews, Meta-Analyses (PRISMA) statement, and checklist were used. The inclusion criteria were studies performed in the young population that assessed the efficacy of INT training compared to a control group, with other types of training or with no training. The population considered was both young and athletes. Children up to 11 years old in girls and 13 years old in boys in addition to adolescents between ages of 12 and 18 years old for girls and 14-18 years old for boys, as previously defined by Lloyd et al. [17] were examined. Exclusively, the studies including two or more components of INT (i.e., fundamental and specific movement skills, strength, plyometrics, speed, agility, coordination, dynamic stability, and fatigue resistance) in the training program, which were compared to a control group (i.e., randomized controlled trial or prospective study) were considered. Further, only studies that clearly detailed parameters of exercise containing a description of at least training intensity or volume were included. Finally, only studies published in English after 1 January 2007 were assessed. 


\subsection{Search Strategy}

A literature search was performed in the following electronic databases: PubMed, Cochrane Central Register of Controlled Trials, Web of Science, CINAHL, MEDLINE, and SPORTDiscus. The last search was conducted in January 2018. The search strategies varied according to the different databases and used the following systematic search terms: Neuromuscular control or neuromuscular training or integrative neuromuscular training and strength training, or plyometric training or speed training or agility training or fundamental movement skills or specific movements skills or coordination training or dynamic stability or fatigue resistance and youth athletes or young or adolescents and injury prevention or sport performance. Language was limited to English and participants were all human.

\subsection{Data Collection Process and Quality Analysis}

Two authors (J.S. and B.S.) independently screened titles and abstracts to choose potential eligible studies. Full-text articles were obtained and independently evaluated for inclusion in the present review based on the inclusion criteria. Disagreements were resolved by consensus and, if necessary, the study's authors were contacted for clarification guidance. The flow chart can be observed in Figure 1 . Each study that met the inclusion criteria was abstracted for information regarding: Number of trained and untrained athletes, age and sex, sport, main and secondary outcomes, main results, INT contents included, frequency, duration, and intensity of the training program.
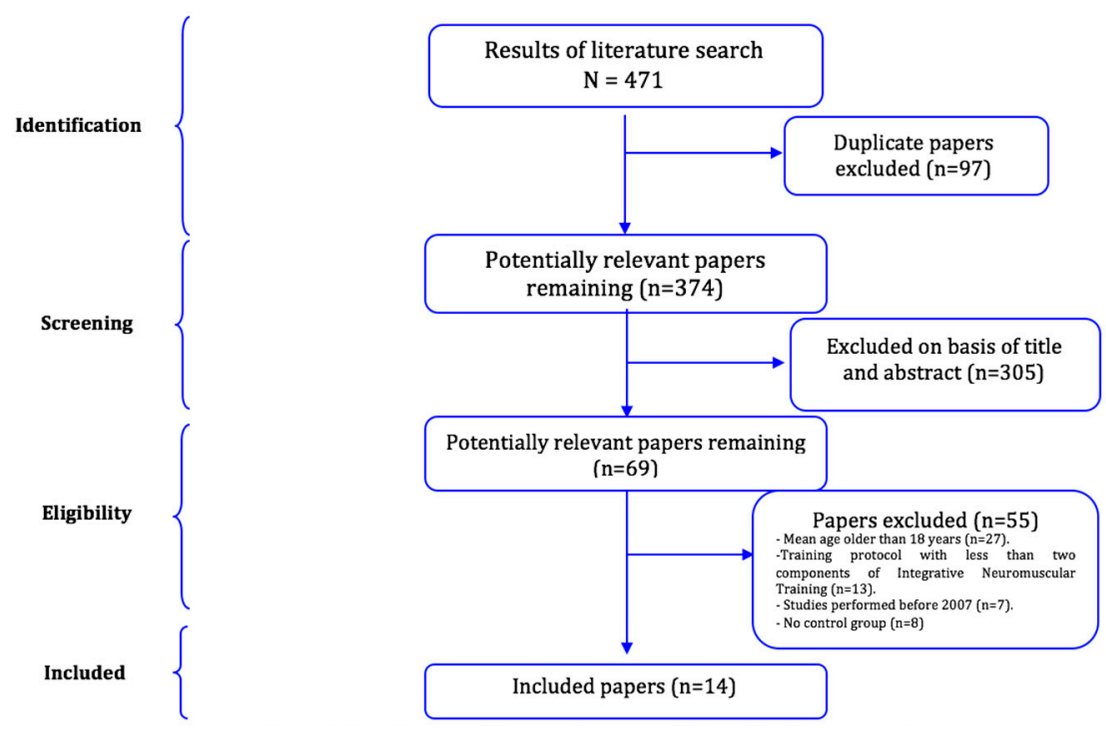

Figure 1. Flow diagram of the search process of integrative neuromuscular training effects in injury prevention and performance on youth athletes.

The methodological quality was individually assessed by using an adaptation of the Cochrane methods [18], which included the generation of randomization sequence, the allocation concealment, blinding of participants or assessors and description of withdrawals and dropouts (see Table 1). 
Table 1. Quality assessment of studies.

\begin{tabular}{ccccc}
\hline $\begin{array}{c}\text { Study } \\
\text { (Author, Year) }\end{array}$ & $\begin{array}{c}\text { Generation of } \\
\text { Randomized } \\
\text { Sequence }\end{array}$ & $\begin{array}{c}\text { Allocation } \\
\text { Concealment }\end{array}$ & $\begin{array}{c}\text { Blinding of Participants or } \\
\text { Assessors }\end{array}$ & $\begin{array}{c}\text { Description of } \\
\text { Withdrawals and } \\
\text { Dropouts }\end{array}$ \\
\hline Barendrecht [19] & No & No & No & Yes \\
Brown [20] & Yes & No & No & Yes \\
Chaouachi [21] & Yes & No & No & Yes \\
Emery [22] & Yes & Yes & No & Yos \\
Faigenbaum [23] & Yes & No & No & Yes \\
Fernandez [24] & No & No & No & No \\
Filipa [25] & No & No & No & Yes \\
Klugman [26] & No & No & No & Yes \\
Lindblom [27] & Yes & No & No & Yes \\
Mcleod [28] & No & Yes & No & Yes \\
Richmond [29] & Yes & No & No & Yes \\
Steffen [30] & Yes & No & & No \\
Steffen [31] & Yes & No & & Noss and assessors \\
Steffen [32] & Yes & & & \\
\hline
\end{tabular}

\section{Results}

The literature search identified 471 potentially relevant studies (Figure 1). Following the screening of the titles, 305 studies were excluded in addition to 97 duplicates. Concerning the eligibility criteria, the remaining 69 studies were analyzed. Ultimately, 55 studies were excluded, 27 were due to the mean age which was higher than 18 years old, 13 included only one component of INT in their training protocols, seven were performed before 2007 and eight studies did not include a control group. This resulted in 14 included studies to be analyzed in the present review.

\subsection{Characteristics of the Included Studies}

Table 2 shows that most studies were executed exclusively on young female population $[20,25-28$, 30-32], four studies analyzed both male and female athletes [19,22,23,29], while two studies [21,24] included only male athletes.

Seven studies analyzed soccer players [22,25-27,30-32] and other studies were performed in handball [19], tennis [24] and basketball players [28]. Moreover, we found one study in players of different sports (i.e., field hockey, volleyball, soccer, and basketball) [20], and three remaining studies were developed in unspecified sports [21,23,29]. Regarding the age of the athletes and the peak of height velocity (PHV), which normally occurs around the age 12 in females and 14 in males [33], in twelve studies [19-22,24-28,30-32] mean age was post-PHV ( $>14$ years old), while only in two studies $[23,29]$ the mean age of the athletes was pre-PHV $(<14$ years old $)$. 
Table 2. Characteristics of the included studies.

\begin{tabular}{|c|c|c|c|c|c|}
\hline Author & Participants & Sport & Age & Main and Secondary Outcomes & Main Results \\
\hline Brown [20] & $\begin{array}{l}\mathrm{N}=43 \text { female athletes. } \\
\mathrm{NMT}, \mathrm{n}=10, \text { CORE, } \mathrm{n}=7 \\
\text { PLYO, } \mathrm{n}=13, \mathrm{CG}, \mathrm{n}=13\end{array}$ & $\begin{array}{l}\text { Basketball, field hockey, } \\
\text { soccer, and volleyball. }\end{array}$ & $\begin{array}{l}\text { NMT: } 14.1 \pm 1.2 \text { years, } \\
\text { CORE: } 15.0 \pm 0.6 \text { years, } \\
\text { PLYO: } 14.8 \pm 0.6 \text { years, } \\
\text { CG: } 14.7 \pm 2.6 \text { years. }\end{array}$ & $\begin{array}{l}\text { FUNDAMENTAL MOVEMENT } \\
\text { SKILLS: Sagittal and frontal planes } \\
\text { hip and knee kinematics and } \\
\text { kinetics. }\end{array}$ & $\begin{array}{l}\text { Greater peak knee flexion following training, } \\
\text { during both bilateral }(p=0.027) \text { and unilateral } \\
\text { landings }(p=0.076, \mathrm{~d}=0.6) \text { was reported in NMT. } \\
\text { PLYO demonstrated reduced hip adduction }(p= \\
0.010) \text { and greater knee flexion }(p=0.065, \mathrm{~d}=0.6) \\
\text { during bilateral landings following training. A } \\
\text { significant time interaction was observed in CG } \\
\text { showing a significant reduction in peak stance } \\
\text { knee abduction moment }(p=0.003) \text {. }\end{array}$ \\
\hline Chaouachi [21] & $\begin{array}{l}\mathrm{N}=42 \text { male athletes. } \\
\mathrm{PLYO}, \mathrm{n}=14 . \text { Balance } \\
\text { and plyometric group } \\
(\text { Bal-PLYO), } \mathrm{n}=14 . \mathrm{CG}, \mathrm{n} \\
=14 .\end{array}$ & $\begin{array}{l}\text { Public school students } \\
\text { with no after school } \\
\text { activities or formalized } \\
\text { strength and conditioning } \\
\text { training programs. }\end{array}$ & $\begin{array}{l}\text { PLYO: } 13.7 \pm 0.8 \text { years, } \\
\text { Bal-PLYO: } 13.3 \pm 0.8 \text { years, } \\
\text { CG: } 13.5 \pm 0.8 \text { years. }\end{array}$ & $\begin{array}{l}\text { STREGNTH, SPEED, DYNAMIC } \\
\text { STABILITY, AND AGILITY: } \\
\text { Lower-body strength test (one } \\
\text { repetition maximum -1RM- leg } \\
\text { press), power test (horizontal and } \\
\text { vertical jumps, triple hop for } \\
\text { distance, reactive strength, and leg } \\
\text { stiffness), running speed (10-m and } \\
\text { 30-m sprint), static and dynamic } \\
\text { balance (standing Stork test and } \\
\text { SEBT), and agility (shuttle run). }\end{array}$ & $\begin{array}{l}\text { Bal-PLYO training was considered likely to be } \\
\text { superior to PLYO training in leg stiffness }(\mathrm{d}=0.7) \text {, } \\
10-\mathrm{m} \text { sprint }(\mathrm{d}=0.6) \text {, and shuttle run }(\mathrm{d}=0.5) \text {. In } \\
8 \text { of the } 11 \text { dependent variables, the difference } \\
\text { between Bal-PLYO vs. PLYO training was unclear. } \\
\text { Bal-PLYO training was considered likely to be } \\
\text { meaningfully better than CG in all dependent } \\
\text { variables }(\mathrm{d}=0.6-1.4) \text {. PLYO training was } \\
\text { considered likely to be meaningfully better than } \\
\text { CG in all dependent variables ( }(\mathrm{d}=0.3-1.2) \text { except } \\
\text { leg stiffness and } 10-\mathrm{m} \text { sprint. }\end{array}$ \\
\hline Emery [22] & $\begin{array}{l}\mathrm{N}=744 \text { male and females. } \\
\mathrm{NMT}, \mathrm{n}=380 . \mathrm{CG}, \mathrm{n}=364\end{array}$ & Soccer & $\begin{array}{l}\text { NMT: U13-15 }=46.6 \% \text {, } \\
\text { U16-U18 }=53.4 \%, \text { Female } \\
=42.4 \%, \text { Male }=57.6 \% \text {, } \\
\text { CG: U13-15 }=48.9 \% \text {, } \\
\text { U16-U18 }=51.1 \%, \text { Female } \\
=69 \%, \text { Male }=31 \%\end{array}$ & $\begin{array}{l}\text { INJURY SURVEILLANCE: Injury } \\
\text { definition was soccer injury } \\
\text { resulting in medical attention } \\
\text { and/or removal from a session } \\
\text { and/or time loss. }\end{array}$ & $\begin{array}{l}\text { Significant differences were found in injury rates } \\
\text { between NMT ( } 2.08 \text { injuries/1000 player-hours) } \\
\text { and CG ( } 3.35 \text { injuries/1000 player-hours). }\end{array}$ \\
\hline Faigenbaum [23] & $\begin{array}{l}\mathrm{N}=40 \text { males and females. } \\
\mathrm{NMT}, \mathrm{n}=10 \text { boys and } 11 \\
\text { girls. } \mathrm{CG}, \mathrm{n}=6 \text { boys and } \\
13 \text { girls. }\end{array}$ & $\begin{array}{l}\text { Children from two } \\
\text { second-grade PE classes } \\
\text { in a public school }\end{array}$ & $\begin{array}{l}\text { All groups: Boys }=7.6 \pm \\
0.3 \text { years, Girls }=7.5 \pm 0.3 \\
\text { years. Total }=7.6 \pm 0.3 \\
\text { years. }\end{array}$ & $\begin{array}{l}\text { STRENGTH, DYNAMIC } \\
\text { STABILITY, AGILITY, AND } \\
\text { FATIGUE RESISTANCE: Push-up, } \\
\text { curl-up, standing long jump, } \\
\text { single-legged hop, single-legged } \\
\text { balance, sit-and-reach flexibility } \\
\text { test, shuttle run, and } 0.8-\mathrm{km} \text { run. }\end{array}$ & $\begin{array}{l}\text { Intervention effects in the girls enhanced } \\
\text { NMT-induced gains in performance relative to CG } \\
\text { on the curl-up, long jump, single-legged hop, and } \\
0.8-\mathrm{km} \text { run }(\mathrm{P}<0.05) \text { after controlling for baseline. } \\
\text { Boys did not demonstrate similar adaptations } \\
\text { from the NMT program }(\mathrm{P} \geq 0.05) \text {. }\end{array}$ \\
\hline Fernández [24] & $\begin{array}{l}\mathrm{N}=16 \text { male athletes. } \\
\mathrm{NMT}, \mathrm{n}=8, \mathrm{CG}, \mathrm{n}=8\end{array}$ & Tennis & $\begin{array}{l}\text { All groups: } 16.9 \pm 0.5 \\
\text { years. }\end{array}$ & $\begin{array}{l}\text { STRENGTH, SPEED, AND } \\
\text { FATIGUE RESISTANCE: Sprint } \\
\text { test (10 and } 30 \text { meters) CMJ, RSA, } \\
\text { and maximal aerobic performance } \\
\text { using a } 30-15 \text { intermittent fitness } \\
\text { test (30-15 IFT). }\end{array}$ & $\begin{array}{l}\text { After training, } 10-\mathrm{m} \text { sprint, CMJ, and RSA were } \\
\text { significantly improved in NMT }(\mathrm{P} \leq 0.05) \text {. }\end{array}$ \\
\hline
\end{tabular}


Table 2. Cont.

\begin{tabular}{|c|c|c|c|c|c|}
\hline Author & Participants & Sport & Age & Main and Secondary Outcomes & Main Results \\
\hline Filipa [25] & $\begin{array}{l}\mathrm{N}=20 \text { female athletes. } \\
\mathrm{NMT}, \mathrm{n}=13 . \mathrm{CG}, \mathrm{n}=7\end{array}$ & Soccer & $\begin{array}{l}\text { NMT: } 15.4 \pm 1.5 \text { years, CG: } \\
14.7 \pm 0.8 \text { years. }\end{array}$ & DYNAMIC STABILITY: SEBT & $\begin{array}{l}\text { Significant improvements in SEBT were observed } \\
\text { in both limbs for NMT in the posterolateral } \\
\text { direction and in the posteromedial direction of the } \\
\text { left limb. }\end{array}$ \\
\hline Klugman [26] & $\begin{array}{l}\mathrm{N}=49 \text { female athletes. } \\
\mathrm{NMT}, \mathrm{n}=15 . \mathrm{CG}, \mathrm{n}=34\end{array}$ & Soccer & $\begin{array}{l}\text { ETG: } 14.1 \pm 0.4 \text { years. CG: } \\
14.7 \pm 1.0 \text { years. }\end{array}$ & $\begin{array}{l}\text { FUNDAMENTAL MOVEMENT } \\
\text { SKILLS: Tuck jump test. }\end{array}$ & $\begin{array}{l}\text { Both groups significantly reduced their landing } \\
\text { and jumping deficits. There was not a significant } \\
\text { interaction of training status between groups. }\end{array}$ \\
\hline Lindblom [27] & $\begin{array}{l}\mathrm{N}=41 \text { female athletes. } \\
\mathrm{NMT}, \mathrm{n}=23, \mathrm{CG}, \mathrm{n}=18\end{array}$ & Soccer & $\begin{array}{l}\text { NMT: } 14.2 \pm 0.7 \text { years. } \\
\text { CG: } 14.2 \pm 1.1 \text { years. }\end{array}$ & $\begin{array}{l}\text { DYNAMIC STABILITY, } \\
\text { STRENGTH, PLYOMETRICS, } \\
\text { AGILITY, ADN SPEED: SEBT, } \\
\text { CMJ, triple-hop for distance test, a } \\
\text { modified Illinois agility test, and } \\
\text { 10-m and 20-m sprint tests. }\end{array}$ & $\begin{array}{l}\text { Non-significant time effects were observed in } \\
\text { NMT from baseline to follow-up. Changes were } \\
\text { observed in CG compared to NMT for a sub-score } \\
\text { of the SEBT and in the modified Illinois agility test } \\
(p<0.05) \text {. }\end{array}$ \\
\hline Mcleod [28] & $\begin{array}{l}\mathrm{N}=62 \text { female athletes. } \\
\mathrm{NMT}, \mathrm{n}=37, \mathrm{CG}, \mathrm{n}=25\end{array}$ & Basketball & $\begin{array}{l}\text { NMT: } 15.6 \pm 1.1 \text { years, CG: } \\
16.0 \pm 1.3 \text { years. }\end{array}$ & $\begin{array}{l}\text { DYNAMIC STABILITY: BESS and } \\
\text { SEBT. }\end{array}$ & $\begin{array}{l}\text { A significant decrease in total BESS errors in NMT } \\
\text { compared with CON }(\mathrm{P}=0.003) \text { was found. NMT } \\
\text { subjects also reported significantly fewer BESS } \\
\text { errors in the single-foam and tandem-foam } \\
\text { conditions than CG and demonstrated } \\
\text { improvements in the single-foam compared with } \\
\text { their pre-test }(\mathrm{P}=0.033) \text {. Between-group changes } \\
\text { at posttest were observed in the lateral, } \\
\text { anteromedial, medial, and posterior directions. } \\
\text { They also improved in NMT compared with CG } \\
(\mathrm{P}<0.05) \text { using the SEBT. }\end{array}$ \\
\hline Richmond [29] & $\begin{array}{l}\mathrm{N}=725 . \mathrm{NMT}, \mathrm{n}=353 \\
(\text { female } 57.2 \% \text {, male } \\
42.8 \%), \mathrm{CG}, \mathrm{n}=372 \\
\text { (female } 57.0 \% \text {, male } 43 \% \text { ). }\end{array}$ & $\begin{array}{l}\text { Physical education } \\
\text { students. }\end{array}$ & $\begin{array}{l}\text { NMT: } 13 \text { years, CG: } 13 \\
\text { years. }\end{array}$ & $\begin{array}{l}\text { INJURY SURVEILLANCE AND } \\
\text { FATIGUE RESISTANCE: Sports } \\
\text { injuries (total, lower extremity } \\
\text { injury, time loss, ankle, and knee } \\
\text { sprain injury) secondary outcomes } \\
\text { also included: waist circumference, } \\
\text { and aerobic fitness (Leger 20-meter } \\
\text { shuttle run test). }\end{array}$ & $\begin{array}{l}\text { The NMT program was efficacious in reducing } \\
\text { sport-related injury rates and improving measures } \\
\text { of adiposity and fitness in the intervention group. }\end{array}$ \\
\hline Steffen [30] & $\begin{array}{l}\mathrm{N}=2020 \text { female athletes. } \\
\text { NMT, } \mathrm{n}=1073 . \mathrm{CG}, \mathrm{n}= \\
947 .\end{array}$ & Soccer. & $\begin{array}{l}\text { All groups: Ages between } \\
13 \text { and } 17 \text { (with } 43 \% \text { in } \\
\text { NMT and } 45 \% \text { in CG with } \\
15 \text { years of age). }\end{array}$ & $\begin{array}{l}\text { INJURY SURVEILLANCE: } \\
\text { Overall injury rate (proportion of } \\
\text { injured players, the incidence of } \\
\text { ankle, knee, groin, hamstrings, and } \\
\text { other injuries). }\end{array}$ & $\begin{array}{l}\text { Neither a difference was observed in the overall } \\
\text { injury rate between NMT ( } 3.6 \text { injuries/1000 h) and } \\
\text { CG ( } 3.7 / 1000 \mathrm{~h} \text { ) nor in the incidence for any type } \\
\text { of injury. Only } 14 \text { out of } 58 \text { intervention teams } \\
\text { completed more than } 20 \text { prevention training } \\
\text { sessions, therefore, the study reported low } \\
\text { adherence to the program. }\end{array}$ \\
\hline
\end{tabular}


Table 2. Cont

\begin{tabular}{|c|c|c|c|c|c|}
\hline Author & Participants & Sport & Age & Main and Secondary Outcomes & Main Results \\
\hline Steffen [31] & $\begin{array}{l}\mathrm{N}=34 \text { female athletes. } \\
\mathrm{NMT}, \mathrm{n}=18 . \mathrm{CG}, \mathrm{n}=16\end{array}$ & Soccer. & $\begin{array}{l}\text { All players were aged } \\
16-18 \text { years }(17.1 \pm 0.8) .\end{array}$ & $\begin{array}{l}\text { STRENGTH, SPEED, AND } \\
\text { SPORT-SPECIFIC SKILLS: } \\
\text { Isokinetic and isometric strength } \\
\text { protocols for the quadriceps and } \\
\text { hamstrings, isometric hip } \\
\text { adduction, and abduction strength, } \\
\text { vertical jump tests, sprint running } \\
\text { and soccer skill tests. }\end{array}$ & $\begin{array}{l}\text { There was no difference between the NMT and CG } \\
\text { for any of the outcome measured. }\end{array}$ \\
\hline Steffen [32] & $\begin{array}{l}\mathrm{N}=226 \text { female athletes. } \\
\mathrm{CTG}, \mathrm{n}=78 . \mathrm{RG}, \mathrm{n}=68 \\
\mathrm{CG}, \mathrm{n}=80\end{array}$ & Soccer. & $\begin{array}{l}\text { All players between } 13 \\
\text { and } 18 \text { years old. NMT: } \\
\text { U16 (57.7\%)-U18 (42.3\%), } \\
\text { RG: U16 (26.5\%)-U18 } \\
(73.5 \%) \text { CG: U16 } \\
(22.5 \%)-U 18(77.5 \%) .\end{array}$ & $\begin{array}{l}\text { DYNAMIC STABILITY, } \\
\text { PLYOMETRICS AND INJURY } \\
\text { SURVEILLANCE: SEBT, single-leg } \\
\text { balance, triple hop, and jumping } \\
\text { over a bar test. Injury risk. }\end{array}$ & $\begin{array}{l}\text { Compared to CG, single-leg balance }(\mathrm{OR}=2.8 \text {, } \\
95 \% \text { CI } 1.1 \text { to } 4.6) \text { and the anterior direction of the } \\
\text { SEBT improved significantly in NMT (OR }=4.7 \text {, } \\
95 \% \text { CI } 2.2 \text { to } 7.1 \text { ), while two-leg jumping } \\
\text { performance decreased (OR }=-5.1,95 \% \text { CI }-9.9 \text { to } \\
-0.2 \text { ). Significant improvements in five of six } \\
\text { reach distances in the SEBT were found, favoring } \\
\text { players who highly adhered to the program (FIFA } \\
11+\text { ). Moreover, injury risk was lower for those } \\
\text { players (IRR }=0.28,95 \% \text { CI } 0.10 \text { to } 0.79 \text { ). }\end{array}$ \\
\hline
\end{tabular}

excursion balance test; CMJ: Countermovement jump test; RSA: Repeated sprint ability; BESS: Balance error scoring system; IRR: Injury rate ratio. 


\subsection{Outcomes Measures}

Dynamic stability related outcomes were assessed in seven studies $[19,21,23,25,27,28,32]$. As defined by Fort-Vanmeerhaeghe et al. [11], the term "dynamic stability" was considered as the training of lower limb dynamic stabilization (with three categories of progression: Static balance, dynamic balance, and dynamic stabilization) and core dynamic stability. Further studies assessed coordination performing fundamental movements [19,20,26] and sport-specific skills [31], while other studies analyzed muscle strength $[21,23,24,27,31]$ and plyometric $[27,32]$ tests. Agility $[21,23,27]$ and speed $[21,24,27,31]$ tests were also considered by different studies. Finally, fatigue resistance $[23,24,29]$ and injury risk $[22,29,30,32]$ were also examined.

Among the selected studies, five $[19,21,25,28,32]$ found significant improvements in dynamic stability. Four of them reported significant increments in Star excursion balance test (SEBT) in the intervention group compared with control participants [21,25,28,32]. Furthermore, positive changes in single leg stability (one-leg hop test) were found [19]. Nevertheless, two studies [23,27] did not report changes between-groups in this outcome.

Significant changes compared to the control group were also observed in coordination performing fundamental movement skills (i.e., jumping and landing technique) in two studies $[19,20]$. Barendrecth et al. [19] showed that the in-season training group had the greatest benefits on knee kinematics and single leg stability. Although, Brown et al. [20] showed a greater peak knee flexion of landings in the neuromuscular training group in both bilateral $(p=0.027)$ and unilateral landings $(p=0.076)$. By contrast, non-significant between-group differences were observed by Klugman et al. [26]. With respect to the sport-specific skills, the only study that assessed this outcome [31] observed no differences between group performances of soccer players after a period of neuromuscular training.

Among the five studies that assessed muscle strength, three reported significant improvements [21, 23,24]. Fernandez et al. [24] showed a $2 \%$ increment in countermovement jump (CMJ) in the experimental group. Moreover, Chaouachi et al. [21] found improvements in 1RM leg press test, CMJ and maximal hopping test in the neuromuscular training group compared with the control group. This agrees with Faigenbaum et al. [23] who reported significant changes in the training group (girls in physical education classes) in the curl up, long jump and single leg hop tests. Notwithstanding, two studies [27,31] did not find any improvement in strength after the training protocol. Neither of the two studies which analyzed plyometric performance reported positive changes between training and control groups [27,32].

Once the agility tests were analyzed, again contradictory results were found. Uniquely, the study performed by Chaouachi et al. [21] reported increments in shuttle run performance $(d=0.52)$. However, non-significant improvements were seen on agility tests in two additional studies [23,27]. This controversy persists in the speed tests results, while two studies found significant differences in $10-\mathrm{m}$ sprint $[21,24]$ and one in 30-m sprint [21], the remaining two studies did not show changes in this outcome $[27,31]$.

With respect to the outcome of fatigue resistance, one study [23] conducted in girls, found positive changes. Moreover, a different study [24] observed significant changes in repeated sprint ability (RSA), with performance increments of $\approx 1.5 \%$, but did not find changes in the 30-15 intermittent fitness test. Contrarily, Richmond et al. [29] showed that the experimental group, submitted to strength and dynamic stability training, had significant improvements in oxygen uptake $\left(\mathrm{VO}_{2 \max }\right)$ in the Leger 20-meter shuttle run test.

With respect to the injury risk, three studies $[22,29,32]$ found significant improvements in the training group compared to the control group. In their study, Emery et al. [22] reported lower injury rates in the training group (2.08 injuries/1000 h) when compared to the control group (3.35 injuries/1000 h). Moreover, Richmond et al. [29] presented an injury rate of 7.1 per 100 students in the experimental group and 14.5 per 100 students in the control group. In a study, Steffen et al. [32] included an experimental group that performed a protocol combining strength, plyometrics, dynamic stability, and 
agility during four months with two, three sessions per week. It was reported that the injury risk is significantly lower in the high adherence group in lower extremities (IRR $=0.28,95 \%$ CI 0.10 to 0.79) when compared with the control group. Uniquely, one of the analyzed studies [30] described no significant changes between groups in injury risk after a period of strength, plyometric, and dynamic stability training (training group $=3.6$ injuries $/ 1000 \mathrm{~h}$, control group $=3.7 / 1000 \mathrm{~h}$ ).

\subsection{Characteristics of the Intervention Programs}

The strength and dynamic stability showed in Table 3 were the contents of INT and were included in the analyzed studies [19-23,25-32]. Plyometric training was used in ten studies [19-22,24,26,28,30-32]. Three studies $[19,20,27]$ included coordination performance fundamental movement skills training in their intervention programs, while four [22,24,28,32] used agility training and two-speed training [20,24].

The length of the exercise programs varied in the included studies from six weeks to eight months. Study duration was six weeks in two studies [20,28], eight weeks in four [21,23-25], and 10 weeks in other three studies [19,26,31]. The remaining studies had a duration of: 11 weeks [27], 12 weeks [29], 16 weeks [32], 20 weeks [22], and eight months [30].

The frequency of the sessions for most studies was two times per week $[19,23-25,27,28]$. The exceptions were four studies in which participants had three training sessions per week $[20,21,26,31]$ and two studies that had a variable duration between two and three sessions per week [29,32]. Conjointly, in one study [30], the intervention group was trained 15 consecutive sessions and thereafter one session per week. Information regarding the number of training sessions per week was not provided in one study [22].

The duration of the sessions was between 15 and $20 \mathrm{~min}$ in most studies [19,22,23,27,29-32], throughout the time, in other three studies, the sessions lasted $60 \mathrm{~min}$ or more $(20,25,28)$. Three studies $[21,24,26]$ did not provide any information related to the duration of the sessions. In these studies, participants performed five to six exercises of strength, plyometric and dynamic stability training [21,26], or plyometric, agility and speed training after eight minutes of dynamic warm-up [24]. 
Table 3. Characteristics of the intervention programs.

\begin{tabular}{|c|c|c|c|c|}
\hline Author & INT Contents & Duration & Frequency & Program \\
\hline Barendrecht [19] & $\begin{array}{l}\text { Strength, plyometrics, dynamic } \\
\text { stability, and coordination. }\end{array}$ & $10 \mathrm{wk}$ & $2 \mathrm{x} / \mathrm{wk}$ & $\begin{array}{l}\text { NMT: } 20 \mathrm{~min} / \mathrm{session}, 6 \text { min warm-up, including agility exercises, } \\
\text { coordination }(4 \mathrm{~min}), \text { balance }(4 \mathrm{~min}) \text {, and strength-plyometric } \\
\text { exercises ( } 6 \mathrm{~min}) . \\
\text { CG (RT group): Received their usual handball training. }\end{array}$ \\
\hline Brown [20] & $\begin{array}{l}\text { Strength, plyometrics, dynamic } \\
\text { stability, speed, and coordination. }\end{array}$ & $6 \mathrm{wk}$ & $3 x /$ wk & $\begin{array}{l}\text { NMT }=60 \text { min standard neuromuscular training (core strength, } \\
\text { balance, plyometrics, resistance, and speed training). } \\
\text { PLYO = } 20 \text { min plyometric exercises. } \\
\text { CORE }=20 \text { min of core and balance training. } \\
\text { CG = Daily activities. All training programs included an active } \\
\text { warm-up (jogging, stretching, side-shuffle, and backward run) and } \\
\text { self-selected stretching ( } \approx 10 \mathrm{~min}) \text { immediately before and after each } \\
\text { session. }\end{array}$ \\
\hline Chaouachi [21] & $\begin{array}{l}\text { Strength, plyometrics, and dynamic } \\
\text { stability. }\end{array}$ & $8 w k$ & $3 x / w k$ & $\begin{array}{l}\text { Bal-PLYO and PLYO did five different exercises per session (strength, } \\
\text { plyometrics and dynamic stability), } 1 / 2 \text { sets of } 8-15 \text { reps. } \\
\text { CG: Regularly scheduled physical education class. }\end{array}$ \\
\hline Emery [22] & $\begin{array}{l}\text { Strength, agility, plyometrics, and } \\
\text { dynamic stability. }\end{array}$ & $20 \mathrm{wk}$ & Not provided & $\begin{array}{l}\text { NMT: } 5 \text { min warm-up including aerobic, static and dynamic } \\
\text { stretching components to be completed in } 5 \text { min, in addition to } 10 \\
\text { min of INT (i.e., strength, agility, balance) and a 15-min home-based } \\
\text { balance-training program. } \\
\text { CG: } 15 \text { min standardized warm-up (aerobic, static, and dynamic } \\
\text { stretching components) and a home-based stretching program. }\end{array}$ \\
\hline Faigenbaum [23] & $\begin{array}{l}\text { Strength and dynamic stability } \\
\text { training. }\end{array}$ & $8 \mathrm{wk}$ & $2 \mathrm{x} / \mathrm{wk}$ & $\begin{array}{l}\text { NMT: } 15 \text { min sessions of INT followed by regularly scheduled } 43 \text { min } \\
\text { PE class. } \\
\text { CG: Participants only attended their regular PE class. }\end{array}$ \\
\hline Fernández [24] & Plyometrics, agility, and speed. & $8 \mathrm{wk}$ & $2 \mathrm{x} / \mathrm{wk}$ & $\begin{array}{l}\text { NMT: } 8 \text { min dynamic warm-up and combined RS training and ExpS. } \\
\text { CG: Usual tennis training sessions. }\end{array}$ \\
\hline Filipa [25] & Strength and dynamic stability. & $8 \mathrm{wk}$ & $2 \mathrm{x} / \mathrm{wk}$ & $\begin{array}{l}\text { NMT: } 5 \text { min warm-up on agility ladder, } 2 \times 45 \text {-min increments of } \\
\text { lower extremity strength and core stability training, and a 5-min } \\
\text { cool-down that included static and dynamic stretches. } \\
\text { CG: Instructed to continue only their usual activities. }\end{array}$ \\
\hline Klugman [26] & $\begin{array}{l}\text { Strength, plyometrics, and dynamic } \\
\text { stability. }\end{array}$ & $10 \mathrm{wk}$ & $3 x /$ wk & $\begin{array}{l}\text { NMT: Six exercises focused on hamstring strength, plyometrics, and } \\
\text { dynamic stability, progressing every two weeks. } \\
\text { CG: Received no intervention and continued their regular in-season } \\
\text { routine. }\end{array}$ \\
\hline
\end{tabular}


Table 3. Cont.

\begin{tabular}{|c|c|c|c|c|}
\hline Author & INT Contents & Duration & Frequency & Program \\
\hline Lindblom [27] & $\begin{array}{l}\text { Strength, dynamic stability, and } \\
\text { coordination. }\end{array}$ & $11 \mathrm{wk}$ & $2 x / w k$ & $\begin{array}{l}\text { NMT: } 15 \text { min. Six exercises targeting strength, dynamic stability, } \\
\text { landing technique, and proper knee alignment. Each exercise had } \\
\text { four different levels of difficulty. } \\
\text { CG: Instructed to perform their usual football training without any } \\
\text { changes. }\end{array}$ \\
\hline Mcleod [28] & $\begin{array}{l}\text { Strength, plyometrics, agility, and } \\
\text { dynamic stability training. }\end{array}$ & $6 \mathrm{wk}$ & $2 x / w k$ & $\begin{array}{l}\text { NMT: } 90 \mathrm{~min} / \text { session, } 5 \text { min warm-up (jogging, side shuffles, cariocas, } \\
\text { and stretches) followed by (a) strengthening ( } 30 \text { min), (b) plyometrics } \\
\text { (20 min), (c) agility training (10 min), and balance training (10 min). } \\
\text { CG: No training protocol, instructed to continue only their usual } \\
\text { activities. }\end{array}$ \\
\hline Richmond [29] & Strength and dynamic stability. & $12 \mathrm{wk}$ & $2 / 3 x / w k$ & $\begin{array}{l}\text { NMT: } 15 \text { min warm-up to PE class in junior high school. The } \\
\text { warm-up included (a) } 10 \text { min NMT aerobic session and (b) } 5 \text { min } \\
\text { lower extremity strength and dynamic stability component. } \\
\text { CG: A variation of a "current standard of practice warm-up" } \\
\text { including a low-intensity aerobic component }(10 \text { min of low-intensity } \\
\text { jogging around the gym) and static and dynamic stretching } \\
\text { components ( } 5 \text { min). }\end{array}$ \\
\hline Steffen [30] & $\begin{array}{l}\text { Strength, plyometrics, and dynamic } \\
\text { stability. }\end{array}$ & 8 months & $\begin{array}{l}15 \text { consecutive } \\
\text { sessions and } \\
\text { thereafter } 1 x / \text { wk } \\
\text { until the season } \\
\text { completion }\end{array}$ & $\begin{array}{l}\text { NMT: } 20 \mathrm{~min} / \text { session, including } 5 \text { min of jogging before starting the } \\
\text { exercises. } 10 \text { exercises focusing on dynamic stability, strength, and } \\
\text { plyometrics. } \\
\text { CG: Continued with their normal training. }\end{array}$ \\
\hline Steffen [31] & $\begin{array}{l}\text { Strength, plyometrics, and dynamic } \\
\text { stability. }\end{array}$ & $10 \mathrm{wk}$ & $3 x / w k$ & $\begin{array}{l}\text { NMT: } 15 \text { min. } 10 \text { exercises focusing on core stability, neuromuscular } \\
\text { control, and eccentric hamstrings strength. } \\
\text { CG: Warm up as usual, with jogging and ball-based exercises. }\end{array}$ \\
\hline Steffen [32] & $\begin{array}{l}\text { Strength, plyometrics, dynamic } \\
\text { stability, and agility. }\end{array}$ & 4 months & $2 / 3 x / w k$ & $\begin{array}{l}\text { CTG: } 20 \text { min warm-up. } 15 \text { exercises divided into three parts, } \\
\text { including initial and final running exercises with a focus on cutting, } \\
\text { jumping, and landing techniques (parts } 1 \text { and } 3 \text { ) and strength, } \\
\text { plyometrics, agility, and dynamic stability components (part 2). They } \\
\text { did warm-up at the beginning of all practices (all parts) and matches } \\
\text { (just part } 1 \text { and } 3 \text { ). Program was taught and supervised. } \\
\text { RG: They received the information, but program was not taught or } \\
\text { supervised. } \\
\text { CG: Were solely provided with online access to the } 11+\text { program. }\end{array}$ \\
\hline
\end{tabular}

NMT: Training group; CG; control group; PLYO: Plyometric training group; Bal-PLYO: Balance and plyometric training group; CORE: Core training group; CTG: Comprehensive group; RG: Regular training group; INT: Integrative neuromuscular training; PE: Physical education; wk: weeks. 


\section{Discussion}

To the best of our knowledge, this is the first systematic review that analyzes the effects of INT in young population considering the contents used in the intervention programs. The primary purpose of this research was to determine which contents of INT provide better results in terms of injury prevention and performance in young athletes. However, there was a desire to advance one step further in the description of the different parameters that determine the application of the training type (i.e., which frequency, intensity, and volume can optimize the benefits of this type of training).

\subsection{Characteristics of the Included Studies}

Most of the studies in this review included only female athletes [20,25-28,30-32], in addition, there is a lack of studies assessing exclusively male athletes [21,24]. This fact makes it difficult to extrapolate the results to other populations. Furthermore, there is a clear tendency to analyze only soccer players [22,25-27,30-32], suggesting the need to extend the results in other sports. Once the age of the participants was analyzed, we found again that most of the studies focused on post-PHV athletes [19-22,24-28,30-32] and only two studies [23,29] analyzed the effects of INT on pre-PHV athletes. This is an important factor, since we cannot generalize the results obtained from athletes at different maturation stages [34]. In their study, Granacher et al. [34] suggested training different contents depending on the athletes' maturation stage. The study considered that focus on coordination, agility, dynamic stability, and strength is more significant in early stages, which aim to improve the movement techniques at a controlled speed. Whilst in a more advanced stage, youths should be trained more frequently on plyometrics, core, and strength exercises with a greater sport specificity and execution speed. This is a tendency generally followed by the reviewed articles. We observed that in the particular studies that trained pre-PHV athletes only strength and dynamic stability training were utilized [23,29], while the studies performed on post-PHV athletes included alternative contents, such as plyometric training [19-22,24,26,28,30-32].

\subsection{Outcomes Measured}

Concerning the effects of INT in youth injury prevention and performance, it was suggested that dynamic stability can be improved $[19,21,25,28,32]$ with an INT program. Notwithstanding, most studies reported improvements in this outcome. While two studies [23,27] did not find changes, possibly by the cause of the training, it did not have the magnitude or stimulus required to enhance this outcome [23,27], also possibly due to a low player attendance in the training sessions [27].

When the coordination of performing fundamental movement skills was assessed, we found some contradictory results. While significant changes after an INT protocol were reported in two studies [19,20], one study [26] observed non-significant between-group changes. Again, an insufficient application of exercise could give an explanation to these results as the authors themselves indicated. There might be a dose response relationship for improving the fundamental movement skills with INT [26]. By taking a closer look at this study it was found that the training protocol consisted of only six exercises focused on hamstring strength, plyometrics, and dynamic stability. Nevertheless, there were no specific coordination exercises including fundamental movement skills. Furthermore, the same tendency can be observed with the sport-specific skills. One study [31] did not report between-group differences. Subsequently, an INT program of $15 \mathrm{~min}$ per session composed of 10 exercises focusing on strength, plyometric, and dynamic stability training was accomplished. It also concluded that the training volume and intensity for each of the exercises were too low to result in performance improvements. It is necessary that at least $20 \mathrm{~min}$ of INT replace the ordinary warm-up exercises used by the team [31].

As previously reported, there is also a controversy in strength and plyometrics after a neuromuscular training protocol. Further, three of five studies found positive changes in strength $[21,23,24]$, while the remaining of two $[27,31]$ did not report any differences between groups. 
One possible explanation to this lack of effect could be attributable, at least in one of the studies [27], to a low training adherence $(59.6 \pm 14.3 \%)$. It is assumed that a higher adherence to the training program would be necessary to improve this outcome [27,31]. Along the same line, non-significant changes between groups were found in plyometric tests after a period of INT in two studies [27,32]. This was probably due to a combination of the lack of stimulus and low adherence to the training program $[27,32]$.

Moreover, contradictory results were found once more with respect to agility and speed tests. Most of the studies did not report significant changes between-groups in agility [23,27] or speed [27,29] performance. As it was described above, it appears that the adherence to the training programs and training stimulus should have been greater in order to enhance agility or speed performance $[23,27,29]$. Notwithstanding, another possible explanation of the discrepancies in this outcome is the number of contents performed. It has been suggested that performing a 15 min INT program, two times per week, training on only strength and dynamic stability contents $[23,27,29]$, are not enough to improve agility and speed performance.

Fatigue resistance was the only INT content that improved in the three studies, which measured this capacity $[23,24,29]$. Therefore, it can be suggested that an INT program can improve this outcome in young athletes. This can happen after a period of training of 8-12 weeks with two/three sessions per week focused on around 15 min training of dynamic stability and strength contents [23,29] or plyometrics, agility, and speed contents [24].

Finally, regarding the injury surveillance, most of the analyzed studies observed a decrease in the rate of injuries [22,29,30,32]. Exclusively, one study [30] did not report significant results, probably considering the low compliance of the training program. The intervention teams included the INT program (composed of 20 min sessions where 10 exercises were performed focusing on strength, dynamic stability, and plyometrics) in only $60 \%$ of their training sessions during the first half of the season [30]. Due to these findings, the injury risk in athletes is likely to be reduced after an INT program with adequate adherence.

\subsection{Characteristics of the Intervention Programs}

In the literature, strength training is considered as one of the best paradigms to enhance physical performance in youth athletes $[35,36]$. Together with dynamic stability training, the INT content was used more in the training programs analyzed in the current study [19-23,25-32]. Furthermore, strength deficits have been associated with less neuromuscular control, which increases the occurrence of injuries mainly in the lower limbs [12]. In this systematic review, those studies which included strength training in their INT programs reduced the rates of injury [22,29,32]. However, these changes were also accompanied by improvements in dynamic stability [19,21,25,28,32], functional movement skills [19,20], strength [21,23], agility [21], speed [21], or fatigue resistance [23,29]. Nonetheless, four [26,27,30,31] of the 13 articles [19-23,25-32] that used strength training did not find positive changes in any of the outcomes measured. This generates a controversy due to the program characteristics in these articles, which were very similar to those studies that did find significant improvements.

Numerous explanations might be suggested for these discrepancies: (a) Application of exercise, (b) age of participants, and (c) contents included in the program. It could be speculated that it is the combination of training contents, rather than the sum of them individually, that confers the benefits on these young people. In fact, the four studies that did not find positive changes employed only three contents: Strength, plyometrics, and dynamic stability in three studies $[26,30,31]$ and strength, dynamic stability and coordination in another one [27]. The age should be another key factor when programing this content. While pre-PHV athletes will have a neuromuscular type of adaptation, exercises must focus on techniques, postural control, and circum-PHV. Post-PHV athletes will not have just neuromuscular but also structural adaptations. The proposed task should additionally focus on improving technique in more advanced and sport-specific exercises and increasing execution speed [11]. Among the aforementioned studies with limited results, all were post-PHV ( $>14$ years old) 
and one [31] presented the highest mean age of all analyzed studies. This suggests the need for an adjustment of adequate training loads and progression in each content.

Dynamic stability was the other main content used in the intervention programs [19-23,25-32]. Evidence supports the need to train this content due to improvements in the sensorimotor system, which can improve neuromuscular control. This leads to a better joint dynamic stability and, therefore, a decrement in the injury risk [37]. In fact, the youth athletes' inability to maintain postural balance in static and dynamic actions has been associated with an increased likelihood of injury [38]. In the reviewed articles, those which included dynamic stability training in their INT programs also included strength training [19-23,25-32]. Thus, similar improvements were found for both contents, which allowed us to suggest that dynamic stability along with strength training might be a good strategy to improve performance and prevent injuries in young athletes. The literature shows that dynamic stability should be trained through exercises focused on the lower limbs and core [39], which challenges the feed-forward mechanism. This is described as anticipated actions that occur before the sensorimotor system detects changes in the environment [40]. This mechanism is the most important factor of training in order to maintain balance in landing, deceleration and cut off maneuvers, which helps to decrease injury risk [41]. Nonetheless, the lack of these types of exercises can be clearly detected in the training programs described in the reviewed articles [19-32].

Plyometric training was the other content of INT widely included in the intervention programs [19-22,24,26,28,30-32], which has been shown to improve performance and to decrease injury risk in young athletes [13]. In the current review, studies which included plyometric training in their INT programs improved dynamic stability [19,21,28,32], functional movement skills [19,20], strength [21,24], agility [21], speed [21,24], fatigue resistance [24] tests, and reduced injury risk [22,32]. Only three $[26,30,31]$ of the 10 studies [19-22,24,26,28,30-32] that used plyometric training did not report significant changes between-groups. One of the particularities of this INT content is the need for an adequate progression. This progression should start with low-intensity exercises performed at a slow velocity with a proper technique and develop at later stages to higher velocity and intensity drills [13].

In various studies $[19,20,27]$, coordination of fundamental movement skills' training was included in their intervention programs. From these studies, we found two reported significant improvements in fundamental movement skills [19,20] and dynamic stability tests [19]. One study [27] could not find significant changes probably due to the low compliance with the training program (mean player attendance at the training sessions was $59.6 \pm 14.3 \%$ ). These skills are particularly important in pre PHV athletes during sport-specific skills development in circum-PHV and post-PHV athletes [42]. Coordination should be trained at early stages due to the greater neural plasticity that children have at this age [43]. Moreover, children are encouraged to be involved in a variety of sports at this age in order to develop neural adaptations for many skills before sport specialization [11]. Likewise, a proper movement competency not only enhances physical ability but, in addition, is suggested to decrease injury risk [44]. However, none of the studies that included coordination in the program subsequently analyzed the injury rates. Furthermore, it should also be highlighted that the protocol of sport-specific skills was not clearly defined in the analyzed studies. Throughout the same line, four articles $[22,24,28,32]$ that included agility training in their protocols were found. Literature has defined agility as the combination of decision-making process and change of direction [45]. Decision-making will improve overall during adolescence based on the experience acquired by the athletes. Nevertheless, the change of direction technique can be enhanced in pre-PHV [15], probably as the result of the great neural plasticity of these youth athletes [43]. From the reviewed articles that used agility training in their protocols, we found improvements in dynamic stability [28,32], strength [24], speed [24], fatigue resistance [24] tests, and injury prevention [22,32]. Hence, it would be interesting to include these outcomes in the youth training programs to enhance performance and to reduce injury risk.

Regarding speed training, evidence suggests developing this INT content across the different stages of growth [15]. From the reviewed literature, we found two studies $[20,24]$ that included speed 
training in their programs. These studies reported significant improvements in strength [24], speed [24], fatigue resistance [24], and fundamental movement skills [20]. Athletes should start training with the high-velocity capacity and the proper running biomechanics, with plyometric, coordination, and sprint technique exercises. Prior to puberty and before maturation, these parameters are easier to change [46]. However, post-PHV athletes may improve more with a combination of neural basis training mainly focused on strength training [15]. Contrarily, it is remarkable that none of the reviewed studies included detailed fatigue resistance training in their protocols. Since we know that neuromuscular fatigue is an important risk factor in numerous sports injuries [16], central fatigue can decrease the ability to perform complex tasks in sports, which will reduce performance and increase injury risk [47]. Again, at early stages, this content should be focused on the correct technical execution of basic movements (pre PHV) to gradually progress towards small-sided games with higher intensity. Once an athlete has enough competencies, a combination of small-sided games and high-intensity interval training should be included in the training program $[11,48]$.

If the parameters of the exercise are analyzed, the length of the exercise programs varied between six weeks to eight months, with most programs lasting eight weeks [21,23-25]. As it was reported in previous literature, at least four weeks are necessary to generate adaptations [15]. Nonetheless, the goal of INT will be to achieve long-term athlete development, with a multi-year training approach following all stages of growth in youth athletes [15]. Moreover, training frequency varies between one and three sessions per week, with two days per week at the most used frequency [23-25,27,28,31]. According to this finding, manifestly practicing high-intensity INT with two/three days per week on non-consecutive days may be sufficient to produce adaptations in youth athletes [49]. Moreover, the duration of the sessions (which was between $15 \mathrm{~min}$ and $60 \mathrm{~min}$ or more) was $15 \mathrm{~min}$ on average in most of the selected studies $[22,23,27,29,31]$. With respect to this outcome, the literature suggests sessions of $60 \mathrm{~min}$ [50] or between 30 and $90 \mathrm{~min}$ for young athletes [51]. However, for physical education classes, it is also scientifically proven that $15 \mathrm{~min}$ sessions are effective in reducing injury risk [51]. Further analysis of this parameter in future studies is warranted.

It is interesting to note that while most studies disclosed significant improvements with these characteristics [19-25,28,29,32], some others [26,27,30,31] did not find improvements with similar protocols in terms of length of the program, frequency, duration, or INT contents trained. Therefore, it was hypothesized that the main reason for this controversy is the grade of adherence to the training program. Due to the fact that those studies which could not find significant improvements in any outcome measure, reported low adherence to the protocols as the main cause of their results $[26,27,30,31]$. Consequently, this makes the training stimulus lower than previously planned.

\subsection{Limitations and Strengths of This Review}

The main limitation of our systematic review was the lack of a detailed description of the training protocols employed by the included studies. However, in order to overcome this limitation, the authors were contacted to collect the missing data (although the lack of some data persisted in some cases). Moreover, the methodological quality of the included studies is moderate as a result of notable bias in at least six of 14 studies reported. Further, the heterogeneity of the studies (e.g., sample size) limits the discussion of the results. Moreover, only studies published in English language were considered in the current review.

The main strength of this study is the description of the most used INT contents in the literature and their effects on injury prevention and sports performance in the youth population. Additionally, this review analyzed the program characteristics, reporting the most common length, frequency, and duration used by the studies, which accomplished our inclusion criteria.

\section{Conclusions}

In conclusion, this review presents that INT programs can enhance performance and injury prevention in young athletes, as long as the adherence to the training program is adequate. The 
most INT contents used in the reviewed studies were strength, dynamic stability, and plyometrics. These contents were followed by coordination of fundamental movement skills, speed, and agility training. However, none of the studies included all the discussed contents in the same protocol. Finally, lack of protocols that included fatigue resistance and specific movement skills training was reported. This is contrary to the recommendations of the literature highlights, with respect to the benefits of discussed INT contents in young athletes.

Future studies are recommended to analyze the effects of a protocol that include all INT contents in young athletes at different growth stages. Researchers need to pay specific attention to pre-PHV athletes and in boys, where a lack of evidence in the literature was found. Needless to say, new lines of research should include INT programs with more drills that challenge the feed-forward mechanisms. This has been described in the literature as one of the most important factors in order to decrease injury risk.

Author Contributions: Conceptualization, B.S. and J.S.-H.; methodology, M.B.-F.; formal analysis, R.T.; investigation, B.S.; writing - original draft preparation, B.S. and J.N.; writing-review \& editing, B.S. and J.N.; supervision, M.B.; review \& editing, E.A.

Funding: This research received no external funding.

Conflicts of Interest: The authors declare no conflict of interest.

\section{References}

1. Rogasch, N.C.; Dartnall, T.J.; Cirillo, J.; Nordstrom, M.A.; Semmler, J.G. Corticomotor plasticity and learning of a ballistic thumb training task are diminished in older adults. J. Appl. Physiol. 2009, 107, 1874-1883. [CrossRef] [PubMed]

2. Bergeron, M.F.; Mountjoy, M.; Armstrong, N.; Chia, M.; Côté, J.; Emery, C.A.; Faigenbaum, A.; Hall, G.; Kriemler, S.; Léglise, M.; et al. International Olympic Committee consensus statement on youth athletic development. Br. J. Sports Med. 2015, 49, 843-851. [CrossRef] [PubMed]

3. Hewett, T.E.; Myer, G.D.; Ford, K.R. The influence of growth and pubertal maturation on neuromuscular performance in high-risk female athletes. Med. Sci. Sports Exerc. 2002, 34, S247. [CrossRef]

4. Quatman-Yates, C.C.; Quatman, C.E.; Meszaros, A.J.; Paterno, M.V.; Hewett, T.E. A systematic review of sensorimotor function during adolescence: A developmental stage of increased motor awkward- ness? Br. J. Sports Med. 2012, 46, 649-655. [CrossRef] [PubMed]

5. Myer, G.; Faigenbaum, A. Pediatric physical activity exercise is sports medicine in youth: Integrative neuromuscular training to optimize motor development. Rev. Kronos 2011, 10, 39-48.

6. Myer, G.D.; Ford, K.R.; Foss, K.D.; Goodman, A.; Ceasar, A.; Rauh, M.J.; Divine, J.G.; Hewett, T.E. The incidence and potential pathomechanics of patellofemoral pain in female athletes. Clin. Biomech. 2010, 25, 700-707. [CrossRef]

7. Gianotti, S.M.; Marshall, S.W.; Hume, P.A.; Bunt, L. Incidence of anterior cruciate ligament injury and other knee ligament injuries: A national population-based study. J. Sci. Med. Sport 2009, 12, 622-627. [CrossRef]

8. Bloemers, F.; Collard, D.; Paw, M.C.A.; Van Mechelen, W.; Twisk, J.; Verhagen, E. Physical inactivity is a risk factor for physical activity-related injuries in children. Br. J. Sports Med. 2012, 46, 669-674. [CrossRef]

9. Caine, D.; Purcell, L.; Maffulli, N. The child and adolescent athlete: A review of three potentially serious injuries. Sports Sci. Med. Rehabil. 2014, 6, 22. [CrossRef]

10. Sport \& Fitness Industry Association. Sports, Fitness, and Leisure Activities Topline Participation Report; Sport \& Fitness Industry Association: Silver Spring, MD, USA, 2013.

11. Fort-Vanmeerhaeghe, A.; Romero-Rodriguez, D.; Lloyd, R.S.; Kushner, A.; Myer, G.D. Integrative Neuromuscular Training in Youth Athletes. Part II: Strategies to Prevent Injuries and Improve Performance. Strength Cond. J. 2016, 38, 9-27. [CrossRef]

12. Hewett, T.E.; Myer, G.D.; Kiefer, A.W.; Ford, K.R. Longitudinal increases in knee abduction moments in females during adolescent growth. Med. Sci. Sports Exerc. 2015, 47, 2579-2585. [CrossRef] [PubMed]

13. Lloyd, R.S.; Meyers, R.W.; Oliver, J.L. The natural development and Trainability of plyometric ability during childhood. Strength Cond. J. 2011, 33, 23-32. [CrossRef] 
14. Fort-Vanmeerhaeghe, A.; Romero-Rodriguez, D.; Montalvo, A.M.; Kiefer, A.W.; Lloyd, R.S.; Myer, G.D. Integrative Neuromuscular Training and Injury Prevention in Youth Athletes. Part I: Identifying Risk Factors. Strength Cond. J. 2016, 38, 36-48. [CrossRef]

15. Lloyd, R.S.; Oliver, J.L. Strength and Conditioning for Young Athletes: Science and Application; Routledge: Abingdon, UK, 2013.

16. Brazen, D.M.; Todd, M.K.; Ambegaonkar, J.P.; Wunderlich, R.; Peterson, C. The effect of fatigue on landing biomechanics in single-leg drop landings. Clin. J. Sport Med. 2010, 20, 286-292. [CrossRef] [PubMed]

17. Lloyd, R.S.; Oliver, J.L.; Faigenbaum, A.D.; Howard, R.; Croix, M.B.; Williams, C.A.; Best, T.M.; Alvar, B.A.; Micheli, L.J.; Thomas, D.P.; et al. Long-term athletic development-part 1: A pathway for all youth. J. Strength Cond. Res. 2015, 29, 1439-1450. [CrossRef] [PubMed]

18. Higgins, J.P.; Green, S. (Eds.) Cochrane Handbook for Systematic Reviews of Interventions; John Wiley \& Sons: Hoboken, NJ, USA, 2011; Volume 4.

19. Barendrecht, M.; Lezeman, H.C.; Duysens, J.; Smits-Engelsman, B.C. Neuromuscular training improves knee kinematics, in particular in valgus aligned adolescent team handball players of both sexes. J. Strength Cond. Res. 2011, 25, 575-584. [CrossRef] [PubMed]

20. Brown, T.N.; Palmieri-Smith, R.M.; McLean, S.G. Comparative adaptations of lower limb biomechanics during unilateral and bilateral landings after different neuromuscular-based ACL injury prevention protocols. J. Strength Cond. Res. 2014, 28, 2859-2871. [CrossRef]

21. Chaouachi, A.; Othman, A.B.; Hammami, R.; Drinkwater, E.J.; Behm, D.G. The combination of plyometric and balance training improves sprint and shuttle run performances more often than plyometric-only training with children. J. Strength Cond. Res. 2014, 28, 401-412. [CrossRef]

22. Emery, C.A.; Meeuwisse, W.H. The effectiveness of a neuromuscular prevention strategy to reduce injuries in youth soccer: A cluster-randomised controlled trial. Br. J. Sports Med. 2010, 44, 555-562. [CrossRef]

23. Faigenbaum, A.D.; Myer, G.D.; Farrell, A.; Radler, T.; Fabiano, M.; Kang, J.; Ratamess, N.; Khoury, J.; Hewett, T.E. Integrative neuromuscular training and sex-specific fitness performance in 7-year-old children: An exploratory investigation. J. Athl. Train. 2014, 49, 145-153. [CrossRef]

24. Fernandez-Fernandez, J.; Sanz-Rivas, D.; Kovacs, M.S.; Moya, M. In-season effect of a combined repeated sprint and explosive strength training program on elite junior tennis players. J. Strength Cond. Res. 2015, 29, 351-357. [CrossRef] [PubMed]

25. Filipa, A.; Byrnes, R.; Paterno, M.V.; Myer, G.D.; Hewett, T.E. Neuromuscular training improves performance on the star excursion balance test in young female athletes. J. Orthop. Sports Phys. Ther. 2010, 40, 551-558. [CrossRef] [PubMed]

26. Klugman, M.F.; Brent, J.L.; Myer, G.D.; Ford, K.R.; Hewett, T.E. Does an in-season only neuromuscular training protocol reduce deficits quantified by the tuck jump assessment? Clin. Sports Med. 2011, 30, 825. [CrossRef] [PubMed]

27. Lindblom, H.; Waldén, M.; Hägglund, M. No effect on performance tests from a neuromuscular warm-up programme in youth female football: A randomised controlled trial. Knee Surg. Sports Traumatol. Arthrosc. 2012, 20, 2116-2123. [CrossRef] [PubMed]

28. McLeod, T.C.V.; Armstrong, T.; Miller, M.; Sauers, J.L. Balance improvements in female high school basketball players after a 6-week neuromuscular-training program. J. Sport Rehab. 2009, 18, 465-481. [CrossRef]

29. Richmond, S.A.; Kang, J.; Doyle-Baker, P.K.; Nettel-Aguirre, A.; Emery, C.A. A school-based injury prevention program to reduce sport injury risk and improve healthy outcomes in youth: A pilot cluster-randomized controlled trial. Clin. J. Sport Med. 2016, 26, 291-298. [CrossRef] [PubMed]

30. Steffen, K.; Myklebust, G.; Olsen, O.E.; Holme, I.; Bahr, R. Preventing injuries in female youth football-A cluster randomized controlled trial. Scand. J. Med. Sci. Sports 2008, 18, 605-614. [CrossRef] [PubMed]

31. Steffen, K.; Bakka, H.M.; Myklebust, G.; Bahr, R. Performance aspects of an injury prevention program: A ten-week intervention in adolescent female football players. Scand. J. Med. Sci. Sports 2008, 18, 596-604. [CrossRef]

32. Steffen, K.; Emery, C.A.; Romiti, M.; Kang, J.; Bizzini, M.; Dvorak, J.; Finch, C.F.; Meeuwisse, W.H. High adherence to a neuromuscular injury prevention programme (FIFA 11+) improves functional balance and reduces injury risk in Canadian youth female football players: A cluster randomised trial. Br. J. Sports Med. 2013, 47, 794-802. [CrossRef] 
33. Malina, R.M.; Bouchard, C.; Bar-Or, O. Growth, Maturation, and Physical Activity; Human Kinetics: Champaign, IL, USA, 2004.

34. Granacher, U.; Lesinski, M.; Büsch, D.; Muehlbauer, T.; Prieske, O.; Puta, C.; Gollhofer, A.; Behm, D.G. Effects of Resistance Training in Youth Athletes on Muscular Fitness and Athletic Performance: A Conceptual Model for Long-Term Athlete Development. Front. Phys. 2016, 7, 164. [CrossRef]

35. Lloyd, R.S.; Faigenbaum, A.D.; Stone, M.H.; Oliver, J.L.; Jeffreys, I.; Moody, J.A. Position statement on youth resistance training: The 2014 international consensus. Br. J. Sports Med. 2014, 48, 498-505. [CrossRef] [PubMed]

36. Faigenbaum, A.D.; Myer, G.D. Pediatric resistance training: Benefits, concerns, and program design considerations. Curr. Sports Med. Rep. 2010, 9, 161-168. [CrossRef] [PubMed]

37. Lloyd, R.S.; Oliver, J.L.; Faigenbaum, A.D.; Myer, G.D.; De Ste Croix, M.B.A. Chronological age versus biological maturation: Implications for exercise programming in youth. J. Strength Cond. Res. 2014, 28, 1454-1464. [CrossRef] [PubMed]

38. Plisky, P. Star excursion balance test as a predictor of lower extremity injury in high school basketball players. J. Orthop. Sports Phys. Ther. 2006, 36, 911-919. [CrossRef] [PubMed]

39. Gamble, P. Strength and Conditioning for Team Sports: Sport-Specific Physical Preparation for High Performance; Routledge: Abingdon, UK, 2013.

40. Riemann, B.L.; Lephart, S.M. The sensorimotor system, part I: The physiologic basis of functional joint stability. J. Athl. Train. 2002, 37, 71-79. [PubMed]

41. Holmes, A.; Delahunt, E. Treatment of common deficits associated with chronic ankle instability. Sport Med. 2009, 39, 207-224. [CrossRef]

42. Morgan, P.J.; Barnett, L.M.; Cliff, D.P.; Okely, A.D.; Scott, H.A.; Cohen, K.E.; Lubans, D.R. Fundamental movement skill interventions in youth: A systematic review and meta-analysis. Pediatrics 2013, 132, e1361-e1383. [CrossRef]

43. Zetou, E.; Vernadakis, N.; Tsetseli, M.; Kampas, A.; Michalopoulou, M. The effect of coordination training program on learning tennis skills. Sport J. 2012, 15, 1-7.

44. Stodden, D.; Langendorfer, S.; Roberton, M.A. The association between motor skill competence and physical fitness in young adults. Res. Q. Exerc. Sport 2009, 80, 223-229. [CrossRef]

45. Young, W.B.; James, R.; Montgomery, I. Is muscle power related to running speed with changed of direction? J. Sports Med. Phys. Fit. 2002, 42, 282.

46. Barlett, R. Introduction to Sports Biomechanics: Analysing Human Movement Patterns; Routledge: Abingdon, UK, 2007.

47. Borotikar, B.S.; Newcomer, R.; Koppes, R.; McLean, S.G. Combined effects of fatigue and decision making on female lower limb landing postures: Central and peripheral contributions to ACL injury risk. Clin. Biomech. 2008, 23, 81-92. [CrossRef] [PubMed]

48. Harrison, C.B.; Gill, N.D.; Kinugasa, T.; Kilding, A.E. Development of aerobic fitness in young team sport athletes. Sports Med. 2015, 45, 969-983. [CrossRef] [PubMed]

49. Myer, G.D.; Faigenbaum, A.D. Exercise is sports medicine in youth: Integrative neuromuscular training to optimize motor development and reduce risk of sports related injury. Rev. Kronos 2011, 10, 39-48.

50. World Health Organization. Reproductive Health. Medical Eligibility Criteria for Contraceptive Use; World Health Organization: Geneva, Switzerland, 2010.

51. Faigenbaum, A.D.; Bush, J.A.; McLoone, R.P.; Kreckel, M.C.; Farrell, A.; Ratamess, N.A.; Kang, J. Benefits of strength and skill-based training during primary school physical education. J. Strength Cond. Res. 2015, 29, 1255-1262. [CrossRef] [PubMed]

(C) 2019 by the authors. Licensee MDPI, Basel, Switzerland. This article is an open access article distributed under the terms and conditions of the Creative Commons Attribution (CC BY) license (http://creativecommons.org/licenses/by/4.0/). 